\title{
STRESS ANALYSIS EXPERIMENTS FOR MECHANICAL ENGINEERING STUDENTS
}

\author{
Nashwan Younis \\ Department of Engineering \\ Indiana University-Purdue University Fort Wayne \\ Fort Wayne, IN 46805-1499
}

\begin{abstract}
This paper examines the experimental determination of assembly stresses in members utilizing the optical method of reflected photoeleasticity. It is essential that students understand the basic concepts in Mechanics of Materials; the paper discusses experiments that can be used by advanced undergraduate students to visualize and understand the development of stresses in structural members. The experiments and design projects outlined, combined contact, bearing, and axial stresses; the experiments were designed and constructed for the use of mechanical engineering undergraduate courses. The suggested experiments and design projects for these non-traditional combined structural stresses are included to improve the students' comprehension in upper-level Experimental Mechanics course or Machine Design course.
\end{abstract}

Introduction

The ever-increasing demand from industry for more sophisticated structural and machine components requires a solid understanding of the concepts of stress, strain, and the behavior of materials. At the sophomore level, students in a mechanical engineering (ME) program are introduced to the concepts of stress and strain in a solid body through the Mechanics of Materials course. In the first Machine Design course, junior mechanical engineering, the students learn to calculate the bolt/rivet and joint members stresses. Due to the time constraints of a first Mechanics of Materials course there is generally insufficient time to verify the assumptions made in developing the theories with experimental verification. Experimental validation allows the student to delve into the corresponding approximate nature of these theories.

The Stress Analysis Laboratory practice improves the students' comprehension of the stress theory learned in lecture. The literature that was examined used many different experimental stress analysis methods and experimental designs to enhance the learning of the mechanics concepts. One paper proposed the optical method of caustics to study the effects of the presence of a crack in machine components and structural members ${ }^{1}$; experiments were included to visually demonstrate to the students the state of stress at a crack tip. The use and importance of numerical methods in designing and dimensioning of machine components is increasing. However, Franz et. al showed the benefits to students of using photoelastic experiments beside numerical calculation ${ }^{2}$. Many cases used the electrical-resistance strain gages to interest the students in learning Mechanics of Materials. The design, construction, and calibration of a 
simple strain-gage based liquid densitometer integrated fluid and solid mechanics for the students ${ }^{3}$. Szaroletta enhanced the traditional C-clamp combined stress laboratory experiment by adding several strain gage instrumentations; the result was expanded learning opportunities for the students ${ }^{4}$.

A basic Mechanics of Materials course normally deals with a combined loading topic in the analysis of stresses and strains produced by three fundamental types of loads: axial, torsional and flexural. Educators must effectively teach about the interaction of the combined loads to prepare the students for industry, in which they will encounter machine and structural elements that are subjected to a combination of these three types of loads.

The literature review showed that many articles have been written about the use of experiments that deal with the combination of axial, torsional, and flexural loads; the literature is bereft when describing the other combinations of loads that the students will encounter. In this paper, the author demonstrated an experimental teaching approach that combined stresses using the interaction between axial, contact, and bearing stresses. These stresses were demonstrated by the use of joint connections, not studied in other articles.

Advantage of using photoeleasticity

Strain gages are used widely in the instruction of Experimental Stress Analysis; the gages are used to measure the strain in structural members and machine components. The students learn of strain gage techniques in the Strength of Materials laboratory or in an instrumentation course. Optical methods such as Caustics and Moiré are not normally studied until a student is in graduate studies. Strain gages are point measurements and the problems of discrete averaging are well documented ${ }^{5}$.

In the proposed experiment, stresses change rapidly and conventional strain gages cannot reflect these changes. The author explains experiments that can be used by students to demonstrate the non-linear stress distribution resulting from the interaction between contact and bearing stresses in the vicinity of bolts. The author chose to add reflected photoelasticity to the Experimental Mechanics laboratory as it is a full field measurement and not a point measurement as seen with strain gages.

It is important that the students visualize the nature of the quantities being computed. To enhance the students' overall understanding of the multiple aspects of structural strength, the behavior of stressed members is discussed in this paper. Stress development visualizations are accomplished by utilizing the experimental method of reflected photoelasticity. The accuracy of the proposed experiments derives from the fact that the physical stress models must obey the practical laws of physics rather than the theoretical laws of numerical mathematics, which may be disobeyed. The accuracy can be accomplished as the method gives direct strain measurements on real parts under static or dynamic loads; no modeling is required.

Mechanical Engineers and Mechanical Engineering students look for practical problems and practical experimental techniques in which to learn. The reflected photoelasticity method, also known as photostress, is a practical and versatile technique for experimental stress analysis. The 
applicability of the experimental method of reflected photoelasticity extends over a range of practical engineering areas. For example, O'Brien ${ }^{6}$ showed the advantages of using the method to analyze the stresses in the design of aircrafts. Examples of using the technique included landing gear, wing spar and main landing gear support structure, and engine pylon fittings. Strelow et al. ${ }^{7}$ described the use of the method during the design of a prototype military track shoe utilizing a cast metal matrix composite. Mahinfalah and $\mathrm{Harms}^{8}$ used reflected photoelasticity to determine the stress field around a circular hole through one wall of bone.

Setting

In general, the proposed experiments and design projects introduce the students to a practical experimental technique of reflected photoelasticity for the evaluation of stresses in a member. The objectives of the experiments that used a specimen in uniaxial tension show the student the following:

1. The development of stress in a member

2. The region where the theoretical axial stress equation is valid

3. The effects and determination of assembly stress

4. The interaction of normal, bearing, and contact stresses

Equipment and specimen

The experiment setup is shown in figure 1; equipment, specimen, and parts needed are:

1. Tensile machine

2. Reflection polariscope

3. Manual null-balance compensator or photoelasticity digital strain indicator

4. Aluminum specimen coated with photoelastic coating material

5. Small end plates

6. Bolts, nuts, and washers

7. Torque wrench with an adjustable setting

Experiments

Two experiments are suggested to improve the students' comprehension of topics learned in both a sophomore Mechanics of Materials and an upper level Machine Design course or Experimental Mechanics course. In a non-experimental mechanics course, the students may use coated specimens and concentrate on collecting data. Where possible, both the null-balance and tardy compensation methods should be used. Calibration of photoelastic coating is essential and can be done following the procedures outlined in the literature ${ }^{9}$. The dimensions of the specimens used are shown in Fig. 2.; different thickness and length can be used. 


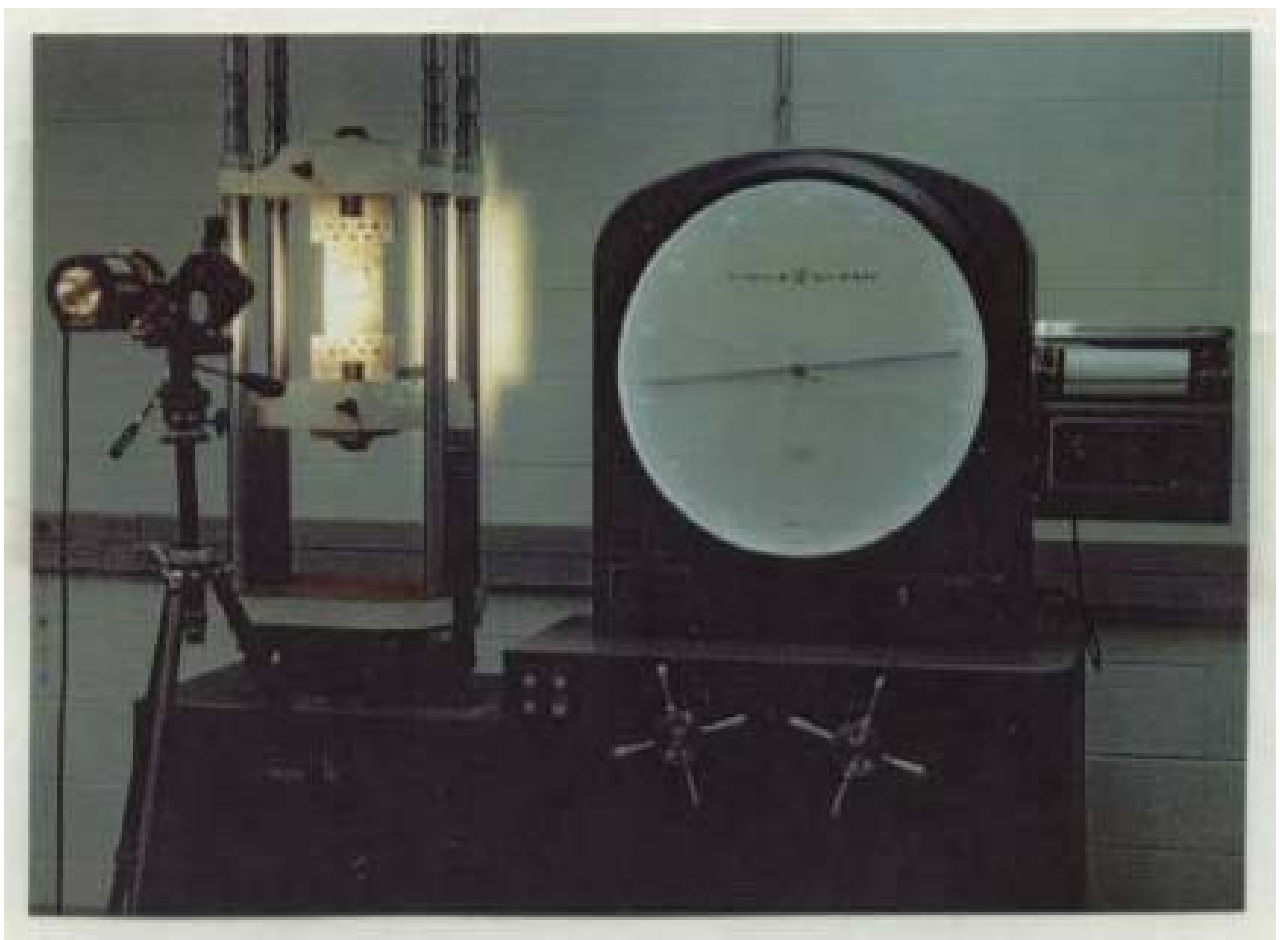

Fig. 1. Experimental setup

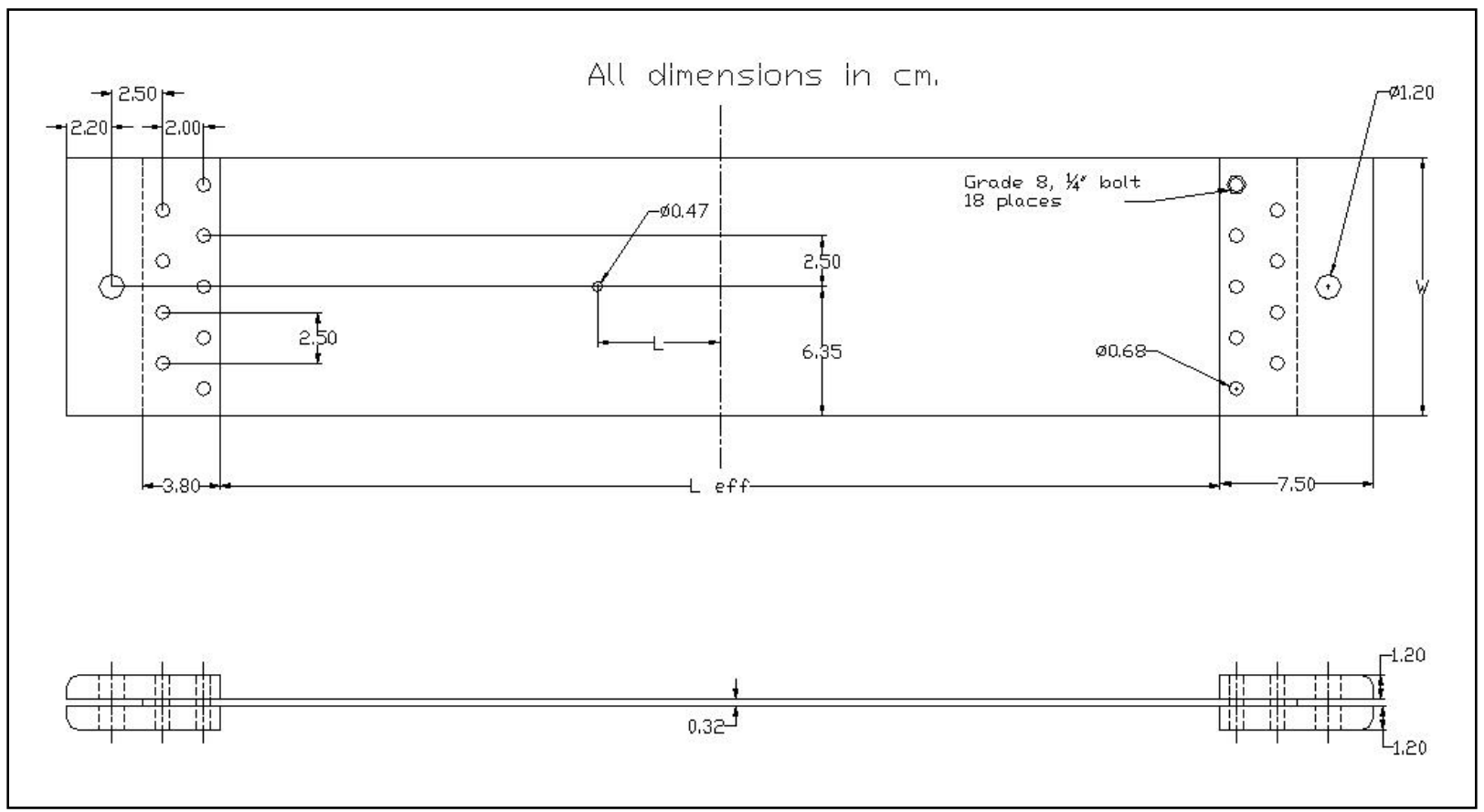

Fig. 2. Sketch of Specimen

Proceedings of the 2003 American Society for Engineering Education Annual Conference \& Exposition Copyright (C) 2003, American Society for Engineering Education 
Experiment \#1: Simple tension test

A specimen that is coated, entirely or partially, with photoelastic material can be used. The bolts and nuts should barely touch the stiffeners, (torque .0), to minimize the effect of contact stress significantly. The objectives of this exercise are for the student to:

1. Visualize the development of axial stress in the member.

2. Establish the region where the strain is uniform; thus compare the validity of the theoretical centric stress equation learned in lecture with a practical engineering situation.

3. Calculate the axial stress and compare it to the theoretical one, $\Phi=\mathrm{P} / \mathrm{A}$.

4. Calculate and study the distribution of the bearing stress resulting from the bolts on the specimen.

5. Determine the directions of the principal strains and stresses.

Typical results obtained for this experiments are shown in Fig. 3. The coating displays the strains in a colorful, informative pattern that reveals the strain distribution. In addition, the fringes' colors and patterns pinpoint the highly strained points as well as the unstressed areas; this full field stress distribution cannot be achieved with strain gages. The students can plot the strain distribution at different distances from the fixtures.

\section{Design Project 1}

Current technical advances and radical designs make the use of reflected photoelasticity ideal in the establishment of design criteria as well as the weight reduction. This is because the fringe pattern is rich with information and insights for the design engineer. Therefore, a design project can be assigned using the specimen(s) utilized in experiment \# 1. The purpose of the project is to verify the design stresses or to further refine the design.

There are growing concerns for product reliability, weight reduction, and material conservation. Mechanical engineers seek valuable design information on how to modify a part to make it lighter, especially seen in the aerospace industry, and at the same time have fewer stresses. Stress analysis, utilizing photoelastic coating, leads to corrective measures for preventing failure, which usually involves material removal.

Proposed project: The weight of a structural component used in the aerospace industry that is subjected to a $8896 \mathrm{~N}$ axial load, like the one shown in Fig. 2, is to be reduced by five percent. Suggest a method to reduce the weight.

By examining the strain distribution in Fig. 3, the students should recognize the area of zero stress that is indicated by the black fringes. In addition, the students may note that the overstressed zone is usually surrounded by an area of near zero stress. However, removing this section gradually may lead to a stress concentration that is beyond the scope of this exercise. 


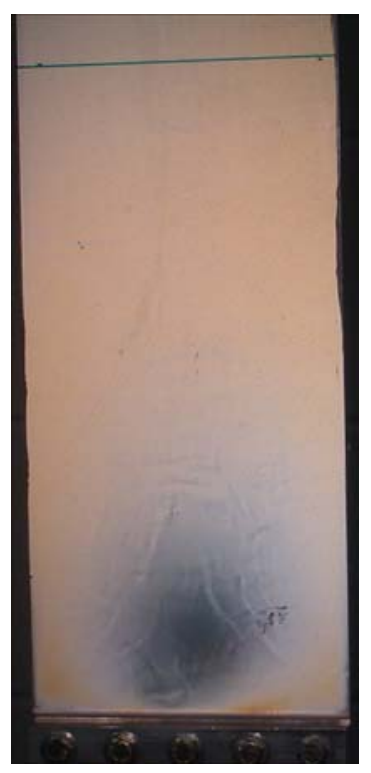

$\mathrm{P}=4448 \mathrm{~N}$

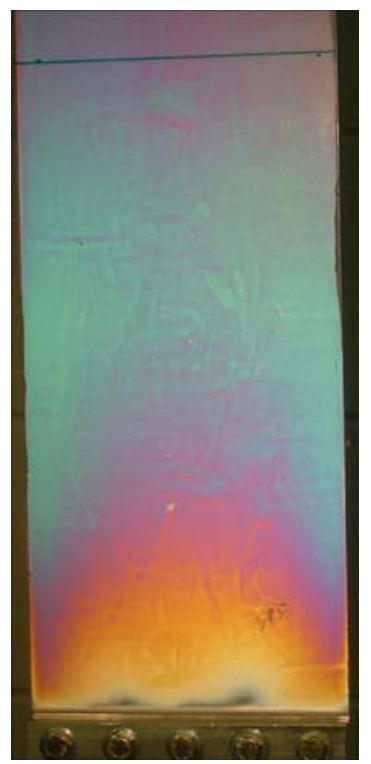

$\mathrm{P}=17792 \mathrm{~N}$

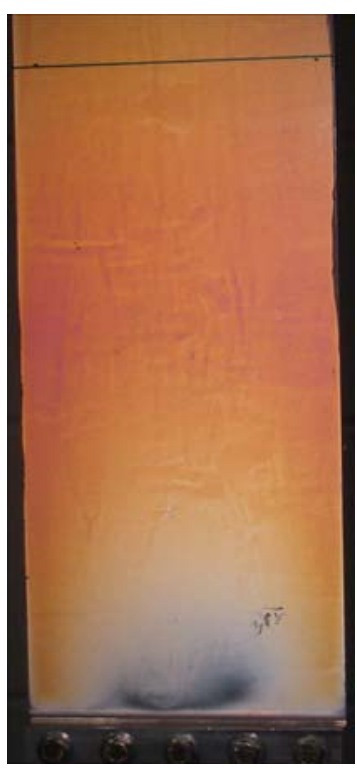

$\mathrm{P}=8896 \mathrm{~N}$

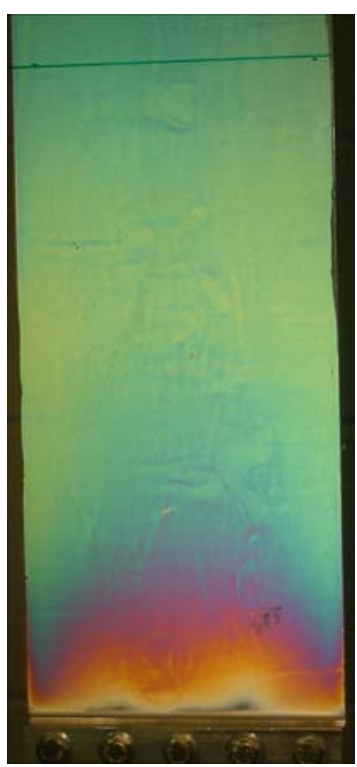

$\mathrm{P}=22240 \mathrm{~N}$

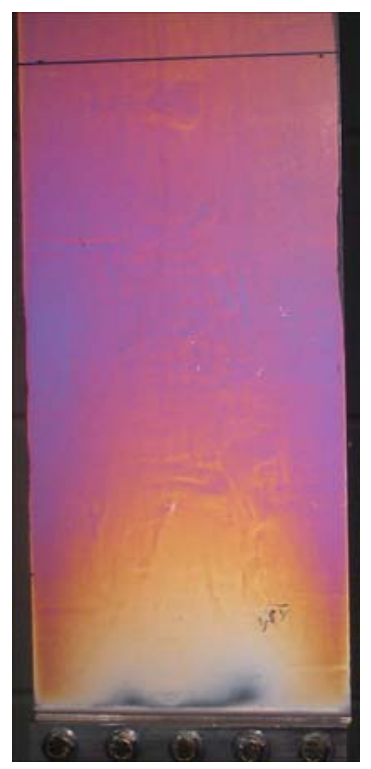

$\mathrm{P}=13344 \mathrm{~N}$

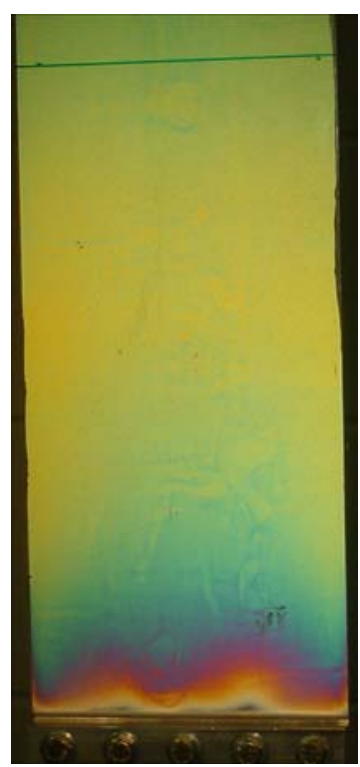

$\mathrm{P}=26688 \mathrm{~N}$

Fig. 3. Photoelastic images for torque $=0$ 
Experiment \#2: Study of assembly stresses

It is recommended that an entirely coated specimen be used in this experiment so two different assembly stresses can be studied and compared at the same time. The objectives of this experiment are:

1. To determine the effect of the bolt's preload on the effective part of the plate, the surface has no pressure. This can be accomplished by using a torque wrench with an adjustable setting in order to ensure a specified torque on the bolts with a high accuracy. The torque can be varied at intervals of 2.5-3.4 N.m. As an example, the difference in principal strains (maximum shear strain) using a null balance compensator for $\mathrm{T}=13$ N.m and zero external load is plotted versus location from the center bolt as shown in Fig. 4. The photoelastic strain distributions in the plates for different bolt torques for an external applied load of $11120 \mathrm{~N}$ and $20016 \mathrm{~N}$ are shown in Figs. 5 and 6, respectively. 2. To teach the students the measurement techniques of both tensile and compressive stresses from the resulting fringe pattern.

3. Study the interaction between axial, bearing, and contact stresses. The students can superimpose the experimental data and the theoretical centric strain. The resulting compressive bearing stress with zero torque on the bolts was determined in experiment 1 , and the theoretical axial tensile stress resulting from the applied external load is P/A. Thus, by superposition the contact stresses in the vicinity of the fixtures can be calculated.

For a load of $11120 \mathrm{~N}$, the students can observe from the black fringe that the axial stress is zero in the vicinity of the central bolt for the torques used. It is beneficial to the students to observe the photoelastic fringe development stages at different loads for the coated part. Aside from the esthetically pleasing character, the development of the fringe pattern is rich with information for students. Full-field interpretation of fringe patterns, aids the students in the overall assessment of nominal strain magnitudes and gradients. Examining the intensity and the patterns of fringes for a $20016 \mathrm{~N}$ load, the students can distinguish the difference in the localized high stress zone compared to the $11120 \mathrm{~N}$ load.
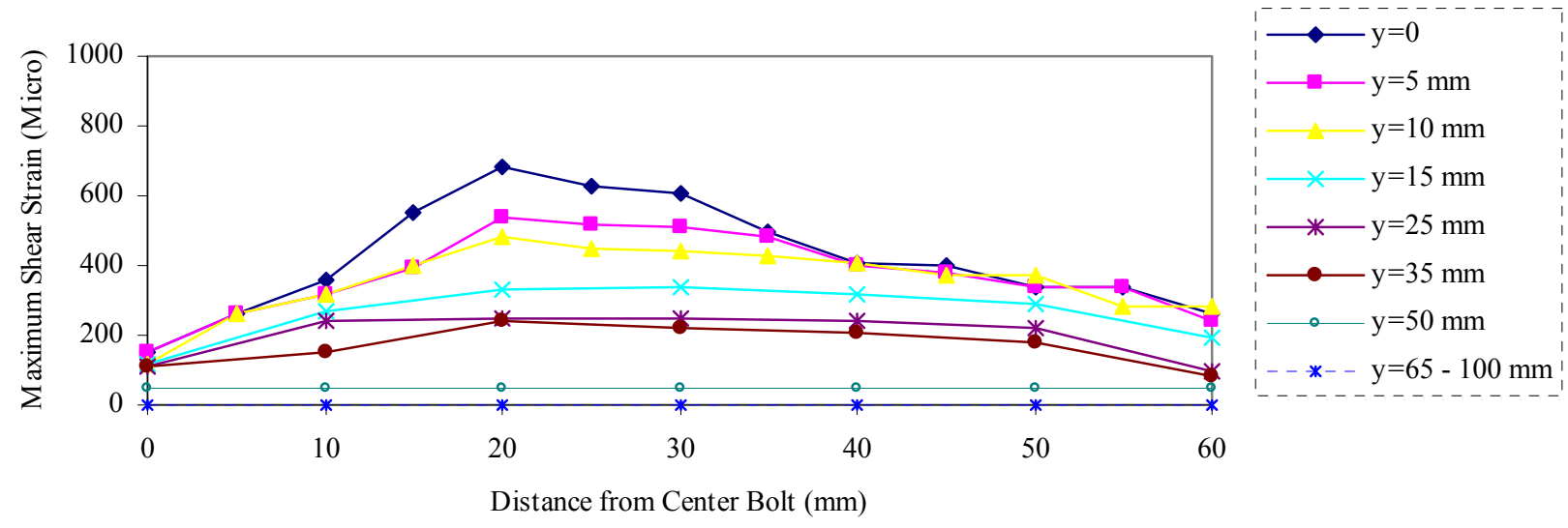

Fig. 4. Maximum shear strain versus location 


\section{Design project 2}

In this design project, the students are introduced to the experimental stress concentrations around a circular hole. The reflected photoelasticity is a powerful method for the visualization of the development of stress concentrations. By using the method, the difference in principal strains (maximum shear strain) can be measured. However, in uniaxial applications and edges of holes, one of the principal stresses is zero. Hence, one measurement is needed to calculate the maximum stress.

Proposed project: One of the design requirements for the member shown in Fig. 2 is to drill a hole when it is subjected to an $11120 \mathrm{~N}$ load. If the member is subjected to a $20016 \mathrm{~N}$ load or greater, two smaller holes are required to pass small cables through the plate. Suggest a location where the holes should be drilled without exceeding the value of axial stress significantly.

In the first case, the hole should be drilled around the center of the near zero stress area. For a $20016 \mathrm{~N}$ load, the students should investigate the area surrounding the cusp point in the vicinity of the central bolt where the stress is very low regardless of the torque magnitude.

\section{Conclusions}

Stress analysis experiments and design projects are proposed for the enhancement of learning some of the Mechanics of Materials and Machine Design fundamentals. The experiments described in this paper are a valuable addition to the content of an undergraduate Mechanical Engineering laboratory. It has been established that by using the method of reflected photoelasticity, it is possible to determine the effect of assembly stress on a two-force member. It would also be possible to drill circular holes with the same diameter at different locations to study the effect of combined bearing, contact, and axial loads on the stresses in the vicinity of the holes. It is worth mentioning that for the same size hole, the stress concentration factor is a function of the location of the hole ${ }^{10}$. It has been shown that by using reflected photoeleasticity, a full field stress distribution study can be achieved; the advantage over strain gages to the students' comprehension of strain measurement is enormous. 


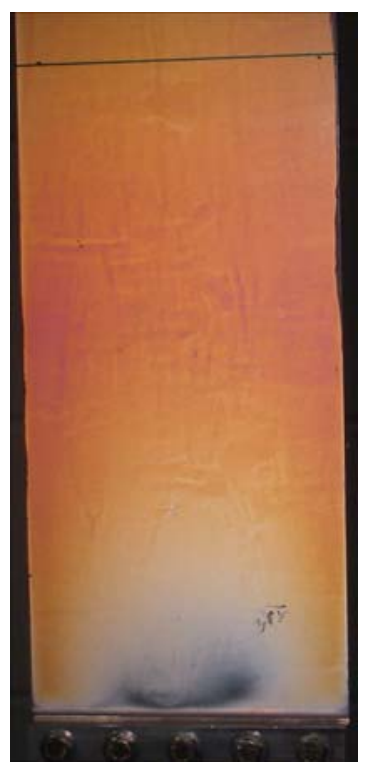

$\mathrm{T}=0$

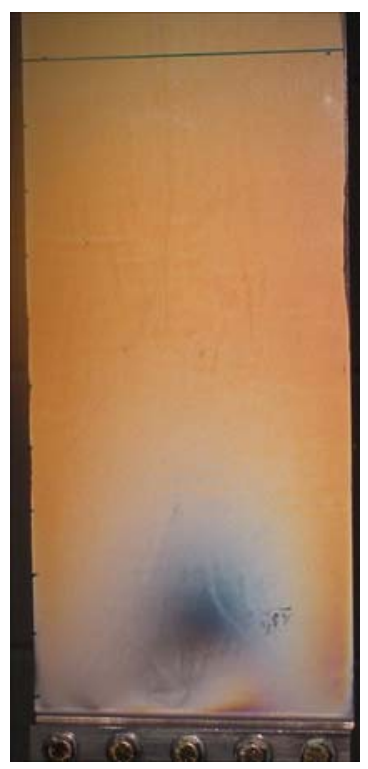

$\mathrm{T}=2.82 \mathrm{~N} . \mathrm{m}$

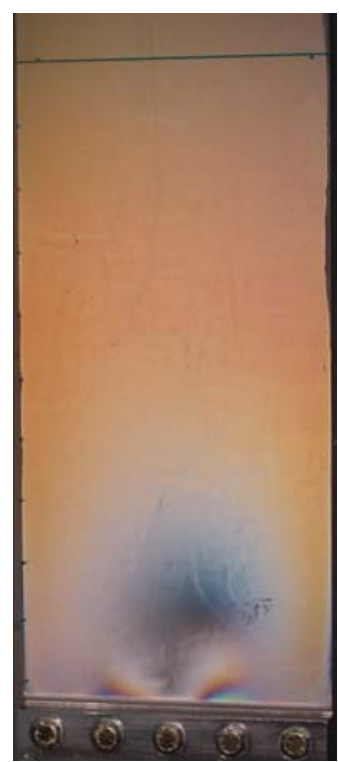

$\mathrm{T}=3.38 \mathrm{~N} . \mathrm{m}$

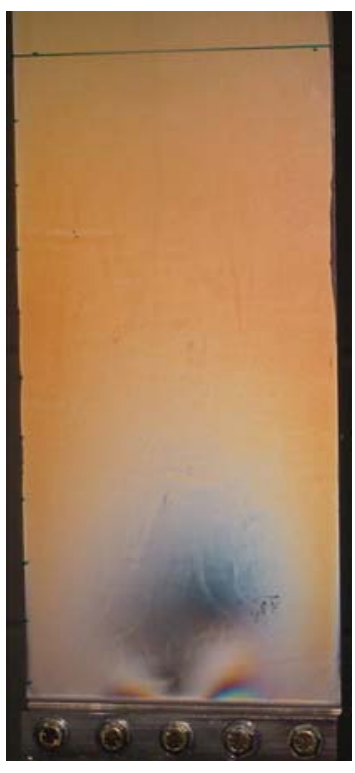

$\mathrm{T}=5.24 \mathrm{~N} . \mathrm{m}$

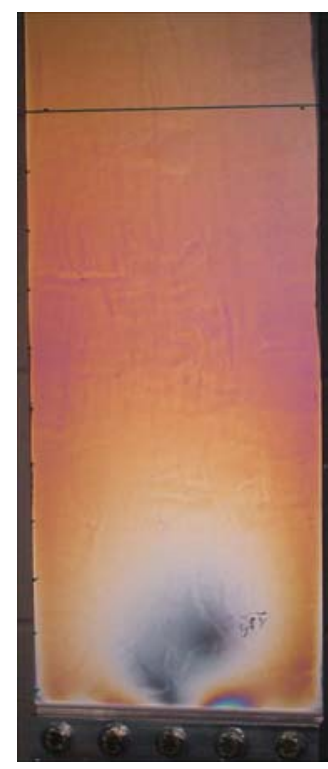

$\mathrm{T}=7.1 \mathrm{~N} . \mathrm{m}$

Fig. 5. Images for different torques at applied load of $11120 \mathrm{~N}$ 


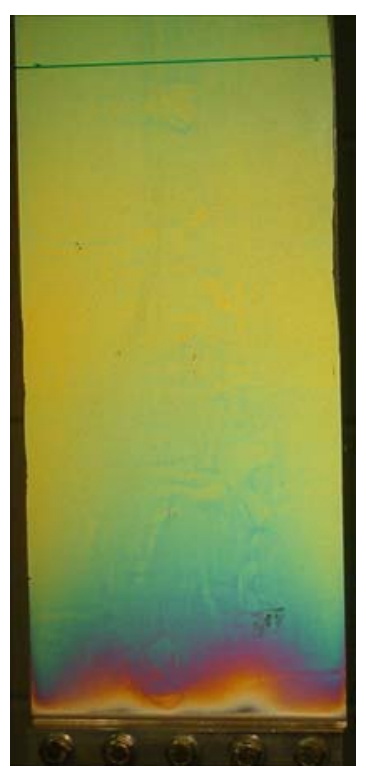

$\mathrm{T}=0 \mathrm{~N} \cdot \mathrm{m}$

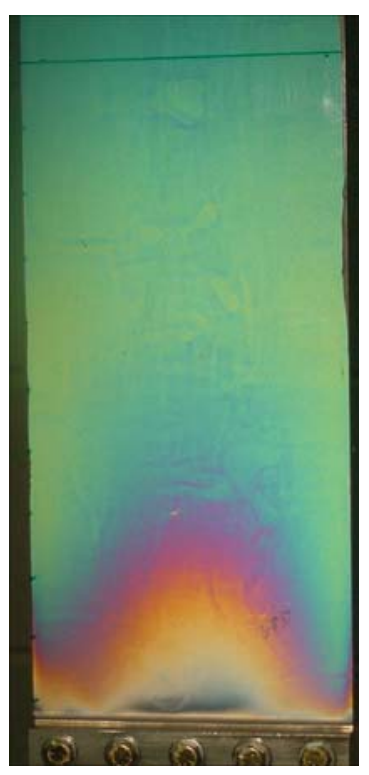

$\mathrm{T}=2.82 \mathrm{~N} . \mathrm{m}$

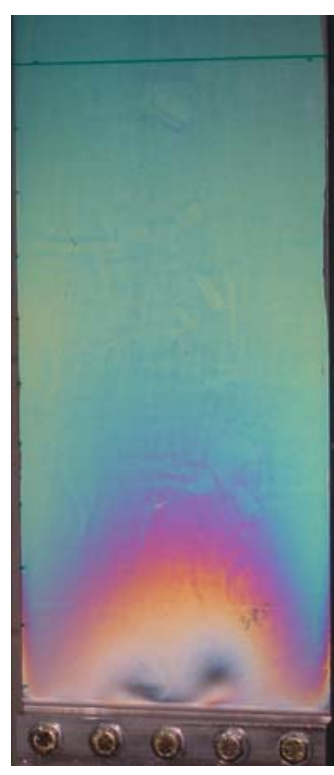

$\mathrm{T}=3.38 \mathrm{~N} . \mathrm{m}$

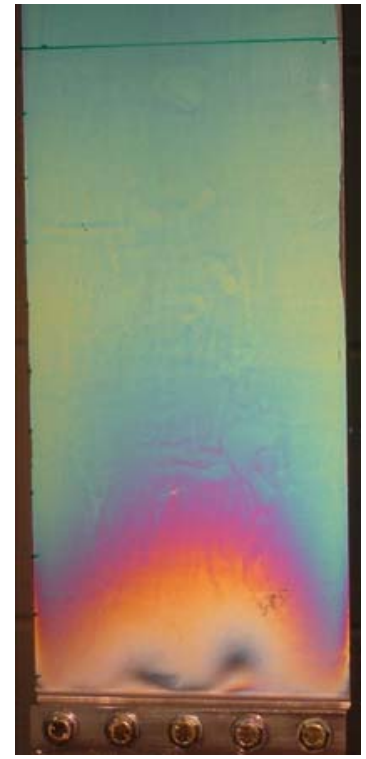

$\mathrm{T}=5.24 \mathrm{~N} . \mathrm{m}$

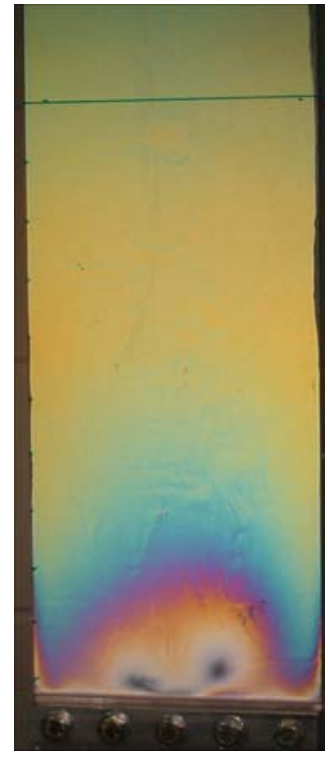

$\mathrm{T}=7.1 \mathrm{~N} . \mathrm{m}$

Fig. 6. Images for different torques at applied load of $20016 \mathrm{~N}$ 
Bibliography

1. N. T. Younis and J. N. Libii, "Mode I Stress Intensity Factor by the Method of Caustics," The International Journal of Applied Engineering Education, Vol. 7, pp. 294-302, 1991.

2. T. Franz and D. H. Mueller, "Student Laboratory on Applications of Photoelasticity," Abstract Proceedings of the SEM Spring Conference on Experimental Mechanics, Bellevue, Washington, June 2-4, 1997.

3. Experimental Stress Analysis Notebook, Measurements Group, Inc., Issue 18, February 1992.

4. W. K. Szaroletta, "Enhancing Combined Stress Laboratory Learning Opportunities," Proceedings of the 2002 American Society for Engineering Education Annual Conference, Montreal, Quebec, Canada, June 16-19, 2002. Session 2168.

5. N. T. Younis and L. W. Zachary, "Discrete Averaging Effects of a Strain Gage Near a Circular Hole,"

Proceedings of the VII International Congress on Experimental Mechanics, Las Vegas, Nevada, June 8-11, pp. 699704, 1992.

6. O'Brien, E.W., “A Better Than Average Stress Model-Photoelastic Analysis for Airbus Design,” Journal of Aerospace Engineering, Vol. 207, pp. 133-137, 1993.

7. Strelow, J.E., Simuta, G.R., Hughes, C.F., and Pakkala, E.C., "Experimental Analysis of an MMC Military Track Shoe," ASME Design Engineering Technical Conference, Vol. 83, pp. 153-160, 1995.

8. Mahinfalah, M., and Harms, M., "Stress Concentrations Associated with Circular Holes in Cylinders and Bone in Torsion," Experimental Mechanics, Vol. 34, pp. 224-229, 1994.

9. Calibration of Photoelastic Coatings, Measurements Group Tech Note TN-701, 1977.

10. N. T. Younis and D. M. Bredemeyer, "Assembly Stresses Effects Around Circular Holes," Proceedings of the SEM Spring Conference, Grand Rapids, Michigan, June 12-14, pp. 882-888, 1995.

\section{Nashwan T. Younis}

Nashwan T. Younis is an associate professor of Mechanical Engineering at Indiana University-Purdue University Fort Wayne. He received his Ph.D in Engineering Mechanics from Iowa State University in 1988. He is the recipient of the 2002 Illinois/Indiana Section of the American Society for Engineering Education Outstanding Educator Award. In addition to curriculum and assessments issues, his research interests include sensors and optical experimental stress analysis 